\title{
The Comparison of Hardness and Coercivity Evolution in Various Fe-B Based Glasses (Including FINEMET Precursor) during Relaxation and Crystallization
}

\author{
Z. Weltsch ${ }^{a, *}, \mathrm{~K} . \mathrm{KLAM}^{a}$ AND A. $\operatorname{LOVAS}^{b}$ \\ ${ }^{a}$ Department of Materials Technology, GAMF Faculty of Engineering and Computer Science, Pallasz Athéné \\ University, Izsáki út 10., 6000 Kecskemét, Hungary \\ ${ }^{b}$ Budapest University of Technology and Economics, Faculty of Transportation Engineering and Vehicle Engineering, \\ Department of Automobiles and Vehicles Manufacturing, Múegyetem rkp 3., 1111 Budapest, Hungary \\ Inverse relation exists between the hardness and coercivity change within the whole period of structural \\ relaxation in the investigated $\mathrm{Fe}-\mathrm{B}(\mathrm{Si})$ based metallic glasses. This relation is independent of $\mathrm{B}$-content and \\ composition. This inverse relation is no more valid in binary $\mathrm{Fe}-\mathrm{B}$ glasses after the onset of crystallization, \\ when both the hardness and coercivity exhibit rapid increase. In contrast, the inverse relation was in FINEMET \\ type glasses between these properties preserved in the first step of crystallization during the whole period of \\ nanocrystallization.
}

DOI: 10.12693/APhysPolA.131.669

PACS/topics: 75.20.En, 75.50.Kj, 75.50.Vv, 75.60.Ej

\section{Introduction}

The favourable soft-magnetic properties of $\mathrm{Fe}-\mathrm{B}(\mathrm{Si})$ based metallic glasses can be further improved, by applying additional relaxation heat treatments. During these annealing $\left(T_{\text {anneal }}<T_{\text {cryst }}\right)$ predominantly relaxation (stress elimination) occurs [1]. During the stress relaxation several physical properties do change (transport, mechanical etc.), which are not necessarily favourable from the point of view of application (increase of hardness and brittleness) [2-4]. The development of magnetic ultrasoftness in the FINEMET-type nanocrystalline precursors is attributed to development of nanoscale crystalline grain structure [5]. However, the contribution of stress relaxation and the nanograin formation to the excellent soft magnetic properties is not clear, because of the overlapping between the mentioned factors. Therefore, the comparative monitoring of relaxation and crystallization seems to be useful in the mentioned systems. In the present paper, the evolution of coercivity and the hardness will be presented in hypoeutectic Fe-B and FINEMET type glasses.

\section{Experiments: materials, heat treatments and measuring methods}

The hypoeutectic $\mathrm{Fe}-\mathrm{B}\left(\mathrm{FeB}_{14.7}, \mathrm{FeB}_{16}, \mathrm{FeB}_{20}\right)$ as well as FINEMET $\left(\mathrm{Fe}_{73.5-x} \mathrm{Si}_{13.5} \mathrm{~B}_{9} \mathrm{Nb}_{x} \mathrm{Cu}_{1}\right)$ type glassy alloys were prepared by planar flow casting. The heat treatments were performed in resistance furnace, in protective (Ar) atmosphere. Microhardness measurements

*corresponding author; e-mail: weltsch.zoltan@gamf.kefo.hu were performed by CSM Micro Combi Tester. Coercivity measurements are reported in Refs. [6, 7].

\section{Relaxation and crystallization in hypoeutectic Fe-B and FINEMET glasses}

Two basic processes are involved in the present heat treatments: structural relaxation and beginning crystallization. Partial overlap exists between these phenomena from the point of view of investigated properties. The concept of relaxation has more wider and general meaning in the phenomena of liquid quench, than it is usually applied in technical heat treatments of soft magnetic glasses. In the latter case, the temperature of the applied heat treatments is always below the crystallization or the glass transition (range B in Fig. 1). In this figure the relaxation phenomenon is explained. The specific volume and the enthalpy is illustrated for a glass forming liquid as the function of temperature, when the liquid is supercooled. With increasing supercooling the free volume and the heat content decreases (region A).

In the range $\mathrm{A}$, the elementary relaxation steps (elementary atomic displacements) are fast enough $\left(10^{-6}\right.$ $10^{-14} \mathrm{~s}$ ), enabling complete rearrangement leading to internal equilibrium, i.e. over the temperature range $\mathrm{A}$ the system is ergodic. However, as the elementary atomic displacements are slowing down due to the viscosity increase and simultaneously a continuous ordering has started in the liquid (already at around $2 / 3$ melting point), the frequency of the elementary displacements increases typically 10 orders in magnitude, as the temperature of liquid approaches the region $\mathrm{B}$.

The relaxation can already be observed in the time of observation, in the form of property changes (heat evolution, hardness, or coercivity change, which can be 


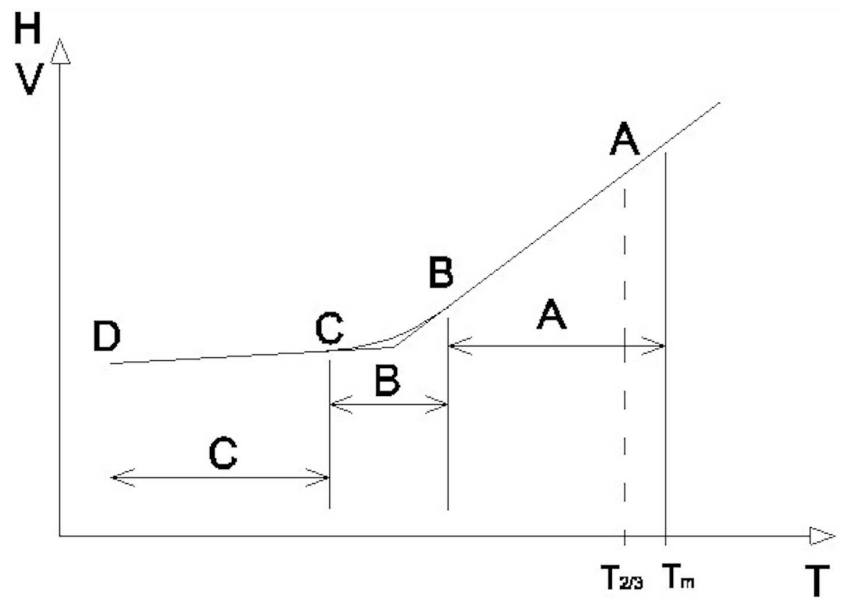

Fig. 1. Illustration of relaxation phenomena in supercooled melt, during glass formation. A: the system is in internal equilibrium; B: relaxation during the experiment; C: the system is totally frozen. $H$ is the change of enthalpy, $V$ - specific volume, $T$ - temperature, $T_{m}$ — melting point [8].

measured in the as quenched glassy state) [9-11]. In the practice of technology, the relaxations are studied in the temperature range $\mathrm{C}$. In this temperature range the system is totally frozen, so the atomic rearrangements and the property changes can be observed in experimental time-scale through the changes of physical properties $[12,13]$ (the atomic mobility is low enough to avoid the crystallization.)

In the following, selected results on the hardness and coercivity change will be presented, obtained after various,"long-time" heat treatments of hypoeutectic Fe$\mathrm{B}$ and FINEMET-type glasses.

\section{Results and discussion}

In Fig. 2 the evaluation of hardness is illustrated for various hypoeutectic $\mathrm{Fe}-\mathrm{B}$ glasses versus the temperature of isothermal annealings. Two ranges can be distinguished in the curves: at low temperatures (below $300^{\circ} \mathrm{C}$ ) the $\mathrm{HV}$ (Vickers hardness) slowly increases as the $T_{\text {anneal }}$ of heat treatments rises (this is typical temperature range of structural relaxation). The $\mathrm{HV}$ in as quenched state and slope of HV ( $\left.T_{\text {anneal }}\right)$ also depend on the B-content, indicating that not solely free-volume annihilation, but also bond-reorientation between the Fe and $\mathrm{B}$ atoms also involved in this process [2]. The rapid increase beyond $300^{\circ} \mathrm{C}$ indicates the crystallization onset in this composition range.

The mechanism of amorphous-crystalline transformation alters at around the eutectic composition [3]. When boron content is lower than 17 at.\%, the differential scanning calorimetry (DSC) exotherm representing the crystallization separates into two peaks. It is important to note that sudden HV increase is associated with the first crystallization step ( $\alpha$-Fe precipitation).

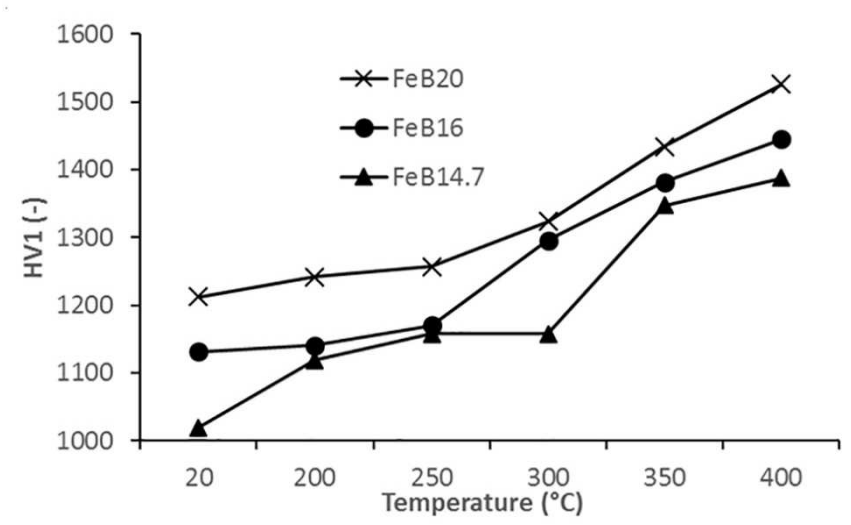

Fig. 2. The change of hardness and coercivity in $\mathrm{Fe}-$ $\mathrm{B}$ glasses during structural relaxation and subsequent crystallization.

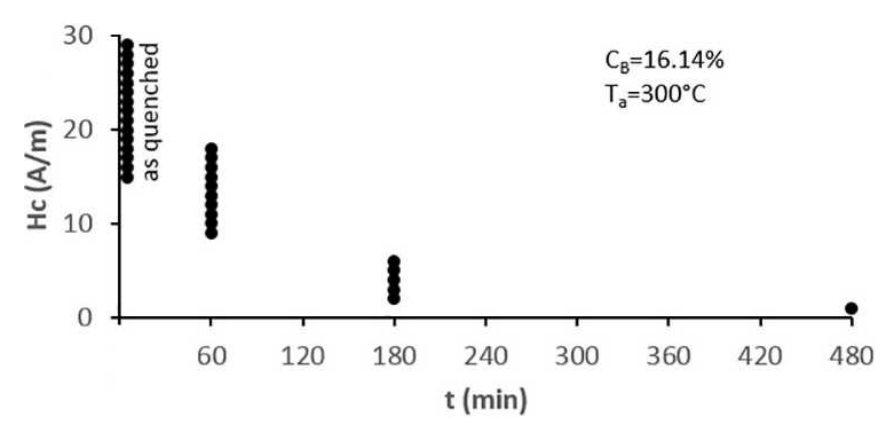

Fig. 3. Coercivity change in eutectic $\mathrm{FeB}_{16}$ glasses during isothermal heat treatments at $300^{\circ} \mathrm{C}$.

The slope of relaxation hardening curve is influenced by the $T_{\text {anneal }} / T_{\text {crys }}\left(T_{\text {crys }}\right.$ is the onset of crystallization step). When the $T_{\text {anneal }}$ is close to the $T_{\text {crys }}$, the slope of hardening curve increases (see Fig. 2).

Opposite to the $\mathrm{HV}$, the coercivity decreases in hypoeutectic $\mathrm{Fe}-\mathrm{B}$ glasses within the whole temperature range of structural relaxation. In Fig. 3 the results of a series of isothermal heat treatments are shown in eutectic $\mathrm{FeB}_{16}$ glasses, performed at $300{ }^{\circ} \mathrm{C}$. Varying quenching

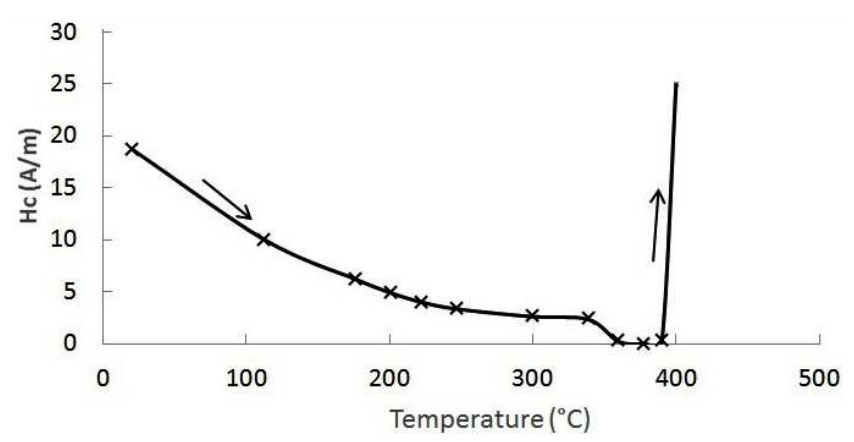

Fig. 4. The coercivity change during continuous heating of an eutectic $\mathrm{FeB}_{16}$ glassy sample. 
conditions were applied during the sample preparation (cooling rate and liquid temperature were altered in order to produce samples with various thermal history, hence varying stress state is resulting in a wide range scattering $H_{c}$ in as quenched state (see Fig. 1 temperature range of " $\mathrm{B}$ "). The range of this scattering is continuously narrowed, with increasing time of heat treatments, showing the significance of the annihilation of stress-centers inherited from the varying quenching condition of liquid.

This tendency turns to opposite, when the critical nuclei of first crystallization process appears. This reversal is illustrated in Fig. 4. The continuously decreasing $H_{c}$ value is plotted here registered during the measurement in eutectic $\mathrm{FeB}_{16}$ glasses. The reversal exhibits the stress-field at the crystallization onset.

Similar to the binary Fe-B glasses, the relaxation hardening is also negligible in the FINEMET alloys (see Fig. 5). The hardness value is nearly constant over a wide range of isothermal heat treatments $\left(450^{\circ} \mathrm{C}\right)$ and sudden increase is detected around the nanograin nucleation (beyond $500^{\circ} \mathrm{C}$ ).

Another important observation is that $\mathrm{HV}$, much lower in this alloy, is probably due to the high Si-content. This low $\mathrm{HV}$ is preserved during the whole relaxation process.

Fig.5. Dependence of $H_{c}$ on the temperature of isothermal annealing in FINEMET alloys. Hardness increases versus the temperature of isothermal annealing in FINEMET alloys

Similarly to the $\mathrm{Fe}-\mathrm{B}$ glasses, sudden $\mathrm{HV}$ increase is typical at the crystallization onset $(\alpha-\mathrm{Fe}(\mathrm{Si})$ precipitation). Opposite to the magnetic hardening in Fe-B glasses, further magnetic softening can be observed, which is associated with the well known exchange softening proposed in Ref. [5].

\section{Conclusions}

1. While inverse relation is found between the hardness and coercivity change in $\mathrm{Fe}-\mathrm{B}(14.7-20$ at.\% B) glasses during the structural relaxation, both properties turn to rapid increase at the crystallization onset.

2. In FINEMET-type precursor glasses this inverse relation is also fulfilled over the whole temperature range of heat treatments, including also the development of $\mathrm{Fe}(\mathrm{Si})$ nanograin system.

3. The hardness of FINEMET-type precursor is lower, compared to the binary $\mathrm{Fe}-\mathrm{B}$ glasses, which indicates that boron content has a dominant role in the overall hardening process in both type of glasses. Si addition acts as a mechanical softening.
4. The impact of structural relaxation on the coercivity decrease is commensurable with the role of nanograin formation in FINEMET $\left(\mathrm{Fe}_{73.5-x} \mathrm{Si}_{13.5} \mathrm{~B}_{9} \mathrm{Nb}_{x} \mathrm{Cu}_{1}\right)$ samples.

\section{Acknowledgments}

This research work was performed as part of the EFOP-3.6.1-16-2016-00014 project in the framework of the New Hungarian Development Plan. The project is supported by the European Union, and co-financed by the European Social Fund, which is gratefully acknowledged.

\section{References}

[1] F.E. Luborsky, in: Amorphous Metallic Alloys, Ed. F.E. Luborsky, Butterworths Monographs in Materials, Butterworths, London 1984, p. 360.

[2] Tsai-Wei Wu, F. Spaepen, Philos. Mag. B 61, 739 (1990).

[3] A. Lovas, É. Kisdi-Koszó, L. Potocky, L. Novák, J. Mater. Sci. 22, 1535 (1987).

[4] A. Singh, Y. Osawa, H. Somekawa, T. Mukai, Mater. Sci. Eng. A 611, 242 (2014).

[5] G. Herzer, Handbook of Magnetic Materials, Ed. K.H.J. Buschow, Vol. 10, Elsevier Sci., Amsterdam 1997, Ch. 3, p. 415.

[6] Z. Pál, J. Takács, Periodica Polytechn. Transp. Eng. 35, 65 (2007).

[7] L. Potocky, L. Novák, É. Kisdi-Koszó, A. Lovas, J. Takács, Acta Phys. Slov. 29, 281 (1979).

[8] C.A. Angel, K.L. Ngai, G.B. McKenna, P.F. McMillan, S.W. Martin, J. Appl. Phys. 88, 3113 (2000).

[9] L. Gránásy, A. Lovas, J. Magn. Magn. Mater. 41, 113 (1984).

[10] Cs. Gulyás, A. Lovas, Periodica Politechn. Ser. Transp. Eng. 32, 91 (2004).

[11] P. Benassi, A. Giugni, M. Nardone, J. Chem. Phys. 135, 034503 (2011).

[12] A.L. Greer, in: Structural Relaxation and Atomic Transport in Amorphous Alloys in Rapidly Solidified Alloys, Ed. H. Liebermann, Marcel Dekker, New York 1993, Ch. 10.

[13] L. Wang, Q. Zhang, X. Cui, F. Zu, J. Non-Cryst. Solids 419, 51 (2015). 